\title{
ENGAGING THE ONLINE STUDENT: INSTRUCTOR-CREATED VIDEO CONTENT FOR THE ONLINE CLASSROOM
}

\author{
Kimber Underdown, Grand Canyon University \\ Jeff Martin, Grand Canyon University
}

\begin{abstract}
The online platform in higher education is growing at a rapid pace; however, detractors claim the lack of personal connection between student and teacher presence will never allow online to reach the same level of quality instruction found in a live classroom setting. While there will always be drawbacks with both the live classroom and online learning platforms, the use of instructor-prepared video in the online classroom has allowed professors to engage their students at a level often higher than that of the traditional classroom experience. This paper will discuss the current literature on the topic of online classroom video and present suggested uses for those given the opportunity to reach students through the virtual classroom setting.
\end{abstract}

Key words: engagement, online instruction, videos, higher education, online teaching

The enormous expansion of the online learning platform in colleges and universities across America has been one of the most impactful educational trends in recent history. Although online education continues to spread rapidly, detractors are quick to point out the deficiencies in this modality of teaching, and some even claim online education will never reach the academic quality level of a traditional ground campus. The lack of instructor interaction is often at the forefront of these complaints (Korkut, Dornberger, \& Marki, 2015). Most online courses rely heavily on student-tostudent interaction to drive discussion rather than direct instruction from faculty as seen in a typical ground class. While the student-only interaction is meaningful and satisfying for some in these classes, others quickly disengage and feel isolated behind the blankness of a computer screen. Strong studentteacher relationships have historically been a key in the satisfaction and ultimate success of a student in a classroom (Draus, Curran, \& Trempus, 2014). Building these meaningful relationships across the Internet is a logistical difficulty for many instructors.
One strategy for doing so is through the creation of personalized video content to be implemented into a self-paced or standard online course to engage students, increase their satisfaction levels with the course, and help them retain a higher level of content knowledge. Studies have determined the inclusion of personalized video content does develop a quasirelationship between teacher and student, and these relationships are the driving factor behind the success of students (Draus et al., 2014; Griffiths \& Graham, 2009; Korkut et al., 2015). This paper contains an examination of several studies into the use of instructor-created video content in the online classroom, and the authors will present practical applications used currently and successfully by online faculty to engage and inspire their students in the online education world.

\section{LITERATURE REVIEW}

There are two primary drawbacks to using an online platform when comparing the content presentation with a ground course. The lack of instructor presence on a regular basis and the diminished lev- 
el of student engagement are concerns for college administrators electing to deliver coursework through an online portal (Draus et al., 2014). Students often feel disengaged and anonymous when enrolled in a self-paced or structured online course. Accountability dwindles, and as a result, participation and assignment quality often suffers. Several studies have examined the value instructor-created video content can have on the levels of student engagement and in the perceived instructor presence in the classroom (Dennen, 2011; Draus et al., 2014; Greenberg et al., 2013; Griffiths \& Graham, 2009). These studies serve as the core of this review of literature.

\section{ENGAGING STUDENTS WITH VIDEO}

One of the primary methods online courses use to measure activity levels and award points within a classroom is chat-style discussion forums. Topics are pre-loaded into a forum and students are expected to participate in class through answering the questions and responding to posts from other students and the instructor. Dennen (2011) determined instructors who embed personalized video content into these forums were able to create environments that encouraged greater levels of student participation and engagement. Students interacted with each other more frequently, and the depth of comments surrounding these inserted videos demonstrated a higher level of analysis than in forums where the questions were simply in text format. The result is not only more satisfied students, but also more successful learners, based on student feedback and a comparison of grades per course (Dennen, 2011).

Kovach, Ding, and O'Neil (2010) conducted a study examining the use of multimedia in the online classroom and its impact on student engagement. The data demonstrated that classrooms where multimedia was used extensively, versus traditional student-driven activities, the levels of student learning and outcomes increased measurably. The authors concluded using podcasts and YouTube videos to deliver content and stimulate conversation among students would help create interest and keep students engaged at higher levels. They claimed the additional time required by faculty to create this content was miniscule compared to the increased student participation and upsurge of student scores (Kovach et al., 2010).

Accurately measuring levels of student engagement can be a difficult challenge to quantify. A 2008 study conducted by Cheung, Hew, and $\mathrm{Ng}$ sought to determine why students elected to either participate or disengage themselves from an online classroom environment. Doing so provided the researchers with a measurable factor to determine active participation levels. The study concluded students who felt a stronger connection with either the instructor or other students were much more likely to remain active in a class. These students participated at levels required to adequately absorb, synthesize, and retain the course material (Cheung, Hew, \& Ng, 2008). Establishing a student-teacher relationship through an online modality can be challenging. Faculty who make the effort to develop their own unique materials to present in class have the opportunity to establish these crucial relationships.

\section{INSTRUCTOR PRESENCE IN THE CLASSROOM}

Studies have determined that the student-teacher relationship was an important component in the success of the online student (Cheung et al., 2008; Korkut et al., 2015). Griffiths and Graham (2009) took this idea one step further and studied the impact of instructor-generated multimedia on the perceived connection between faculty and student. These researchers studied online courses where instructors presented students with content-rich videos. These students reported perceiving a greater connection with the instructor than in a standard lecture-style ground course. Additionally, these students claimed to receive a higher level of attention than a ground course may provide. Although quantifying these factors may be difficult, the perceptions of students are often more important than an actual number or percentage that can be measured.

The perception of an absentee instructor is one plight online courses struggle with continually. Ice, Curtis, Phillips and Wells (2007) studied this phenomenon to determine if implementing instructor-created multimedia into an online classroom had an impact on erasing this misconception. The researchers determined faculty who used videos in the classroom on a consistent basis received much higher feedback scores from students related to the level of faculty engagement in the classroom. Furthermore, it was determined the video content created an increased and active instructor presence in the classroom that helped keep students engaged 
and active. If the students believe an instructor is actively engaged in the classroom and modeling participation and contributing to the group, students are much more likely to follow suit and engage with the instructor and other students in class on a deeper level. The perception is often more powerful than the actual reality in scenarios like these.

Students want to leave a class feeling they have grown as a scholar and have received value from their time and effort. Miller and Redman (2010) studied the perceived satisfaction and perception of value received by students who participated in classes with instructor-created content. The study determined in courses where the instructor implemented multimedia into the standard syllabus content, the levels of student satisfaction and perceived value for the time and money spent on the course improved greatly compared to a standard online class. Additionally, student perceptions of the syllabus content improved, and the comprehension of both assignment expectations and content mastery advanced when compared to a class without video content. Student motivation is an important component determining success in the online education world. Including facultydeveloped video material in an online course will increase student satisfaction, participation, and engagement levels beyond those experiences in a traditional ground classroom or a syllabus-driven online course.

\section{STRATEGIES FOR VIDEO IMPLEMENTATION}

Creating and implementing instructor-led video content into the classroom is simple, yet rewarding. Several different types of videos can be created and used on a regular basis with online courses. A key point for instructors to remember is that any time questions are recurrent, a video is likely to offer a permanent solution for the questions of both current and future students. Creating a video takes only minutes and can easily be implemented in all classes with similar content or questions. A few common videos instructors may want to add to their online teaching repertoire include the welcome to class video, the syllabus overview video and the embedded feedback video for assignments.

\section{The Welcome to Class Video}

In all online courses, there lies the chance that the student is new to online learning, new to the learning management system used, or new to the degree program. To alleviate concerns of new students (or of those who have not fully explored the online system), a welcome to class video shows students the basics of what to do, where to look, and where to find resources. An example welcome video might include a personal introduction by the instructor, including some of the instructor's background and experiences. The video may also include personal instructor requirements that might differ from typical requirements, such as the length of a discussion post or requirement to cite in the discussion forum or the number of posts required to earn full participation credit. The online instructor may also take the students on a virtual tour of the online classroom, pointing out areas to search for assignment details and rubrics, places to ask questions, and basic procedures the student should be aware of. This overview allows students to see and hear their instructor as a real person behind the screen, understand the requirements for successful completion of the course, and have unanswered or common questions answered, even before the questions arise. Once this video has been posted, any time a student has questions answered in the video, the student can be directed to watch the video again. When implementing this type of video, instructors should utilize closed captioning or a script that allows students to follow along with the video visually, as well as audibly.

\section{The Syllabus Overview Video}

Since most instructors do not write the curriculum they teach online, sometimes the directions or requirements for the assignments are not as clear as one might like. The syllabus overview video can alleviate student concerns, clarify expectations, and explain what the instructor will be looking for with regards to student work. Additionally, once this video is created, it can be used any time the instructor teaches the same course, as long as the syllabus requirements have not changed. The syllabus overview video is best created for each week in the course. This is done by detailing the specific week's requirements and content. Once posted in an announcement or a discussion forum, students can refer back to the video for questions on the content. Instructors must use caution when sharing content and syllabus information; however, and be certain that the video is only shared with current students and does not 
violate copyrights. Instructors should be encouraged to ask their administrators about these issues and any accompanying policies, before posting these types of videos.

\section{The Embedded Feedback Video}

Another type of instructor-created video that can increase student engagement and performance is the embedded feedback video. Videos can easily be created to address certain common issues with student assignments. Once created, these videos can easily be embedded as feedback in student work. Common videos that are used for embedded feedback include the thesis statement video, the proofreading and editing video, the video about the specific content addressed in the assignment, and the APA style formatting video. Since embedded instructor feedback is required by most schools, a bank of videos such as these can easily be accessed by instructors and placed in comments for students as a means of improving student success. Students can access these videos, see their feedback visually, and hear their instructor explain it, all with the click of a link.

\section{Student Feedback}

Students are often extremely willing to provide positive feedback about the use of instructor-created video materials. Since today's students are quite literate in a variety of technologies, they appreciate the time and effort their instructor spends creating videos, feel valued as students, and easily have their questions proactively answered through a medium they are often quite comfortable with and proficient in. Some student comments include: "I have not had another professor do that before, and I looked forward to the discussion forums for the additional information, videos, and so forth. Let's put it this way: I enjoyed the WHOLE CLASS!' (Student 1, personal communications, October 31,2015). Student 2 stated, "I really enjoyed the thorough instructions that you provided, especially the video lessons that explained in detail the lessons for the week. This is the first class I have taken that included a video lesson, and I loved it" (personal communications, November 1, 2015). Student 3 stated that she truly enjoyed "....all the videos you posted. It really helped me learn more about the different topics we talked about" (personal communications, November 2, 2015). Overwhelmingly, students provide positive responses to the videos their instructors post in the classroom. Using these videos adds to the effectiveness of the online instructor and creates a positive, engaging atmosphere of learning for the students.

\section{CONCLUSION}

Educators will continue to expand boundaries of the educational envelope with technology and the online learning environment. Online courses allow a university to reach students who may otherwise be prevented from earning a degree at a higher education institution. When compared to traditional ground classes, online courses do have two substantial drawbacks many are quick to identify. Lack of meaningful student engagement and the absence of engaged and present instructors are factors that university administrations are concerned with today (Korkut et al., 2015). Instructors who create and personalize video content for use in their classrooms have seen remarkable results in the engagement and satisfaction levels of students (Draus et al., 2014). Instructors are able to remain at the forefront in a classroom without additional effort on their part. Students feel a greater connection with the instructor, and their efforts and quality of work are greater when compared to those classes without consistent use of instructor-created content (Draus et al., 2014). The online learning platform may never be viewed as perfect; however, with a little creativity on the part of the instructor, students are able to have an equally satisfying educational experience as their ground counterparts with personalized classroom video content. 


\section{References}

Cheung, W., Hew, K., \& Ng, C. (2008). Toward and understanding of why students contribute in asynchronous online discussions. Journal of Educational Computing Research, 38(1), 29-50. http://doi.org/doi:10.2190/EC.38.1.b

Dennen, V. P. (2011). Facilitator presence and identity in online discourse: Use of positioning theory as an analytic framework. Instructional Science, 39(4), 527-541. http://doi. org/doi:10.1007/s11251-010-9139-0

Draus, P., Curran, M., \& Trempus, M. (2014). The influence of instructor-generated video content on student satisfaction with and engagement in asynchronouse online classes. Journal of Online Learning and Teaching, 10(2), 240-254.

Greenberg, J., Mckee, A., Walsh, K., Drake, G., Goldstein, M., Moyer, K., ... Guthrie, C. (2013). Teacher Prep Review: A Review of the Nation's Teacher Preparation Programs. Retrieved from http://eric.ed.gov/?id=ED543515

Griffiths, M., \& Graham, C. (2009). The potential of asynchronous video in online education. Distance Learning, 6(2), 13-22. Retrieved from https://web.archive.org/web/20131111072730/

Ice, P., Curtis, R., Phillips, P., \& Wells, J. (2007). Using asynchronous audio feedback to enhance teaching presence and students' sense of community. Journal of Asynchronous Learning Networks, 11(2), 3-25. Retrieved from http://www. sloanconsortium.org/sites/default/files/v11n2_ice_0.pdf

Kovach, J., Ding, D., \& O'Neil, S. (2010). Using postcasting and video to create valuable student learning experiences. Quality Advances in Higher Education, 1(1), 10-17. Retrieved from http://www.asq.org/edu/2010/02/best-practices/qualityapproaches-in-higher-education-vol-1-

Korkut, S., Dornberger, R., P, D., B, S., \& Marki, M. (2015). Success factors of online learning videos. International Journal of Interactive Mobile Technologies, 9(4), 17-22. http:/l doi.org/http://dx.doi.org/10.3991/ijim.v9i4.4460

Miller, S., \& Redman, S. (2010). Improving instructor presence in an online introductory astronomy course through video demonstrations. Astronomy Education Review, 9(1). http://doi. org/doi:10.3847/AER2009072

\section{Author Biographies}

Kimber O. Underdown is currently an online fulltime assistant professor in the College of Education at GCU and an adjunct for ASD courses at GCU. She also works on curriculum revisions, is a member of many committees, and is the Content Lead for Special Education. Kimber has a B.A. in Special Education, an M.A.T. in Teaching, is ABD in her Ed.D. in Organizational Leadership and is attaining an M.S. in Professional Counseling. Prior to GCU, Kimber worked in the field of special education for 21 years and worked as adjunct faculty at GCU. When she is not teaching, Kimber enjoys spending time with her four children and granddaughter, watching movies, reading, and acting in community theatre productions.

Jeff Martin is an instructor in the College of Education at Grand Canyon University. Prior to joining the staff at GCU, he taught high school and middle school English throughout the state of Arizona for eighteen years. Jeff is currently working on his EdD, and dissertation work is focused on classroom management and the perceptions of novice high school teacher regarding their pre-service training experience. Jeff has presented on the topic of classroom management at various Arizona statewide conferences, and he has a passion for helping teachers in with the critical strategies needed to effectively handle behavioral and management issues in the classroom. 